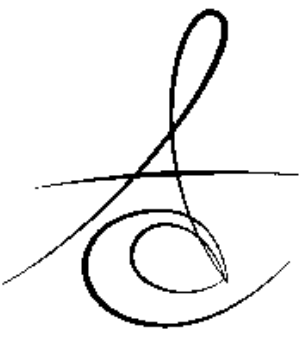

\title{
FARKLI ZAMAN PERIYYOTLARI İLE UYGULANAN GECE KORUYUCULU VITTAL BEYAZLATMA AJANININ GİOMER RESTORATİFLERİN YÜZEY PÜRÜZLÜLÜĞÜ ÜZERİNE ETKİSİ
}

\section{THE EFFECT OF NIGHT-GUARD VITAL BLEACHING AGENT WITH DIFFERENT TIMING PERIODS ON SURFACE ROUGHNESS OF GIOMER RESTORATIVES}

Arş. Gör. Dt. Dilan KARA*

Arş. Gör. Dt. Aslıhan KOÇAK*

\author{
Doç. Dr. Neslihan TEKÇE* \\ Prof. Dr. Emre ÖZEL ${ }^{*}$
}

Makale Kodu/Article code: 3446

Makale Gönderilme Tarihi: 17.04.2017

Kabul Tarihi: 15.02.2018

\section{öz}

Amaç: Bu çalışmanın amacı, farklı zaman periyotları ile uygulanan gece koruyuculu beyazlatma ajanının üç posterior restoratif materyalin yüzey pürüzlülüğü üzerine etkisini incelemektir.

Gereç ve Yöntem: Üç farklı tipte posterior restoratif materyalden [Beautifil-Bulk Restorative (giomer bulkfill), Beautifil II (giomer posterior) ve Aelite LS Posterior (hibrit kompozit rezin)] toplam 90 adet kompozit rezin (disk örneği ( $8 \mathrm{~mm}$ çapında, $2 \mathrm{~mm}$ kalınlıkta) hazırlanmıştır $(n=30)$. Her bir materyal \%16 karbamid peroksit ağartma maddesi içeren Opalescence PF'nin disklere uygulama prosedürlerine göre üç alt gruba ayrılmıştır $(n=10)$. Grup-1: başlangıç ölçümleri; Grup2: 7 gün boyunca günde 4 saat $\% 16$ Opalescence PF uygulaması; Grup-3: 7 gün boyunca günde 6 saat \% 16 Opalescence PF uygulaması. Grupların yüzey pürüzlülük ölçümleri 24 saat ve 1 hafta sonunda profilometre $(\mathrm{Ra}, \mu \mathrm{m})$ ile yapılmıştır. Veriler, iki yönlü varyans analizi (ANOVA) ve Tukey's HSD post-hoc testi ile istatistiksel olarak analiz edilmiştir $(p<0.05)$.

Bulgular: Başlangıç zaman diliminde, Aelite LS Posterior (0.87 Ra), Beautifil-Bulk Restorative (0.70 Ra) ve Beautifil II (0.65 Ra) materyallerinin yüzey pürüzlülük değerleri istatistiksel olarak benzer bulunmuştur ( $>0.05)$. Grup-2 ve Grup-3'te de bu üç materyalin yüzey pürüzlülük değerleri benzerdir. Fakat, Beautifil II'ye 7 gün boyunca 6 saat \%16 Opalescence PF uygulaması sonrasında yüzey pürüzlülüğü önemli düzeyde artmıştır (0.65 Ra'dan 0.95 Ra'ya) ( $p<0.05$ ).

Sonuç: Beautifil-Bulk Restorative ve Aelite LS Posterior, uygulanan test periyotları boyunca yüzey pürüzlülük değişimlerine karşı stabildir. Fakat, Beautifil II'nin \%16 Opalescence PF'nin bir hafta boyunca günde 6 saat uygulanmasından sonra yüzey pürüzlülük değerleri ciddi oranda artmıştır.

Anahtar Kelimeler: Beyazlatma, giomer, yüzey pürüzlülüğü.

\section{ABSTRACT}

Aim: The aim of this study was to examine the effect of night-guard vital bleaching agent with different timing periods on the surface roughness of three posterior restoratives.

Material and Methods: A total of 90 composite resin disc specimens (8 $\mathrm{mm}$ in diameter, $2 \mathrm{~mm}$ in thickness) were prepared from three different types of restoratives [Beautifil-Bulk Restorative (giomer bulkfill), Beautifil II (giomer posterior) ve Aelite LS Posterior (hybrid resin composite)] $(n=30)$. Each group was divided into three subgroups according to application procedures of $16 \%$ carbamide peroxide Opalescence PF bleaching agent $(n=10)$. Group-1: baseline measurements; Group-2: 4 hours/day for 7day; Group-3: 6 hours/day for 7-day. Measurements were conducted at 24-h and 1 week using a profilometer $(\mathrm{Ra}, \mu \mathrm{m})$. The values were statistically analysed with two ANOVA and Tukey's HSD post-hoc test $(p<0,05)$.

Results: At baseline, surface roughness values of Aelite LS Posterior (0.87 Ra), Beautifil-Bulk Restorative $(0.70 \mathrm{Ra})$ and Beautifil II (0.65 Ra) were found statistically similar ( $p>0.05)$. Surface roughness values of these three materials also were found statistically similar for Group-2 and Group-3. However, the values increased significantly for Beautifil II (0.65 Ra to 0.95 Ra) after bleaching agent application for 6 hours per day along 7-day $(p<0.05)$.

Conclusion: Beautifil-Bulk Restorative and Aelite LS Posterior are durable against surface roughness changes in the following test periods. However, surface roughness values of Beautifil II increase significantly after using 16\% Opalescence PF 6 hours per day for one week.

Keywords: Bleaching, giomer, surface roughness

* Kocaeli Üniversitesi Diş Hekimliği Fakültesi, Restoratif Diş Tedavisi AD, Kocaeli. 


\section{GİRİŞ}

Diş estetiğini etkileyen önemli faktörlerden birisi renklenmedir. ${ }^{1}$ Günümüzde estetik beklentilerin artmasıyla estetik uygulamalar popülerlik kazanmıştır. Beyazlatma, doğal dentisyonu koruyabilen ve estetik beklentileri karşılayan invaziv olmayan bir uygulamadır. Geçmişte, renklenmiş dişlere estetik görünüm sağlamak amacıyla daha agresif ve invaziv bir işlem olan protetik yöntemler uygulanırdı. ${ }^{2}$ Günümüzde ise, diş yapısını bozmayan beyazlatma prosedürleri, bu tür problemleri çözmek için önerilmektedir. Beyazlatma prosedürleri ile ilgili önemli aşama, renklenmiş dişlerin vital mi devital mi olduğu ya da prosedürün evde mi yoksa diş hekimi tarafından klinik ortamda (ofis) mı yapılacağının doğru olarak belirlenmesidir. ${ }^{3}$ Ofis tipi yapılan beyazlatmalarda, yüksek konsantrasyonlardaki beyazlatma ajanları diş hekimleri tarafından hastaya uygulanır. Bu amaçla \%15-40'ık hidrojen peroksit jelleri tek başına ya da ısı/ışık uygulanmalarıyla beraber kullanılmaktadır. ${ }^{4,5}$ Çalışmalarda bu jeller ile başarılı sonuçlar elde edilmesine rağmen; 1-2 seans uygulanması işlemin dezavantajıdır. ${ }^{6}$ Hastanın klinik ortamında geçirdiği sürenin azalması amacıyla beyazlatma ajanı ISI, ışık veya lazer ile aktive edilebilir. ${ }^{7}$

Evde uygulanan beyazlatma yöntemleri, ofis ortamında diş hekimi tarafından yapılan beyazlatma yöntemlerine göre daha fazla tercih edilmektedir. ${ }^{8}$ $\% 10$ ile \%16 karbamid peroksit çözeltisi doku ya da tükürük ile temas ettiğinde \%3-5 hidrojen peroksit ve \%7-10 üre olarak ayrışır. Hidrojen peroksit oksijen ve suya dönüşürken, üre, amonyak ve karbondioksit haline dönüşür. Gece koruyuculu uygulanan beyazlatma tekniğinin tedavi süresi hastanın tekniği uygulayarak ne kadar zaman harcadığına göre değişmektedir. ${ }^{9-12}$

Yüzey pürüzlülüğü, plak retansiyonuyla ilişkili olduğu için araştırmacılar ve klinisyenler için önem taşıyan bir konudur. Pürüzlü bir restorasyon yüzeyi, diş eti enflamasyonu ve çürük oluşumuna neden olabilir. Araştırmalarda, kaba yüzeyli restorasyonların glukan yapışmasını ve bakteri kolonizasyonunu arttırdığı da gösterilmiştir. ${ }^{13-15}$

Işık ile polimerize edilen kompozit rezin materyaller, klinik uygulama süresini azaltmak ve restorasyon işlem sürecini hızlandırmak için, kalınlık olarak 4 mm'ye kadar uygulanma imkânı bulmaktadır. Bulkfill kompozit rezinler adını alan bu materyaller özellikle son yıllarda in vivo ve in vitro çalışmalarda sıklıkla kullanılmaktadır. ${ }^{16}$ Günümüzde çok çeşitli bulk-fill kompozit rezinler mevcuttur. ${ }^{17,18}$ Bunlardan bazıları düşük viskoziteli (akışkan) kompozit rezin iken diğerleri yüksek viskozitelidir. ${ }^{19,20}$ Bu bulk-fill kompozit rezinler hastanın tedavi aşamasında zaman kazandırması ve etkinliği açısından giderek popülerlik kazanmaktadır.

Giomer materyaller ise, cam iyonomerlerin klinik avantajlarını koruyacak bir resin restoratif materyal olarak piyasaya sürülmüştür. Zayıf estetik özellik ve dehidratasyon potansiyeli olan cam iyonomerlerin dezavantajları, içeriğe resin materyaller ilave edilerek ve önceden reaksiyona girmiş bir cam iyonomer doldurucu maddesi (PRG) geliştirilerek azaltılmaya çalışımaktadır. ${ }^{21}$ Ön reaksiyona tabi tutulan cam iyonomer parçacıkları (pre-reacted glass-ionomer) diğer bir deyişle PRG doldurucu teknolojisi, bulk-fill teknolojisiyle birleştirilerek, düşük vizkoziteli bulk-fill akışkan giomer materyal (Beautifil-Bulk Flowable, Shofu Dental Corporation) ve yüksek viskoziteli bulk-fill giomer resin restoratif materyali (Beautifil-Bulk Restorative, Shofu Dental Corporation) oluşturulmuştur.

Bu çalışmanın amacı, \%16'lık karbamid peroksit içeren gece koruyuculu beyazlatma ajanının bir giomer bulk-fill, bir giomer posterior ve bir hibrit kompozit rezin üzerindeki etkisinin yüzey pürüzlülüğü açısından incelenmesidir. Oluşturulan hipotezler; 1) Giomerler geleneksel kompozit rezinlerden yüksek pürüzlülük değerleri sergilerler, 2) Giomerler gece koruyuculu beyazlatma ajanı olan \%16'lık karbamid peroksit Opalescence PF uygulaması sonrasında yüzey pürüzlülük artışı sergilemezler, 3) \%16 karbamid peroksit Opalescence PF'nin 1 hafta süresince günde 4 ya da 6 saat uygulanması bu üç materyalin yüzey pürüzlülük sonuçlarını etkilemez.

\section{GEREÇ ve YÖNTEM}

Bu çalışmada üç farklı tipte arka bölge restoratif materyal [Beautifil-Bulk Restorative (giomer bulkfill, Shofu Dental Corporation, San Marcos, Amerika), Beautifil II (giomer posterior, Shofu Dental Corporation, Amerika) ve Aelite LS Posterior (hibrit kompozit rezin, Bisco, Schaumburg, IL, Amerika)] kullanılmıştır. Çalışmamızda kullanılan restoratif materyallerin içerikleri Tablo 1'de gösterilmiştir.

Her materyalden, $8 \mathrm{~mm}$ çapında ve $2 \mathrm{~mm}$ kalınlığında, 90 adet disk şeklinde örnek hazırlanmıştır 
$(n=30)$. Örnekler paslanmaz çelik kalıpların içerisine yerleştirildikten sonra, şeffaf polyester bant altında (Mylar, Henry Schein, Melville, NY, Amerika) cam lamel ile basınç uygulanarak polimerize edilmiştir. Polimerizasyon işlemi için, $1200 \mathrm{~mW} / \mathrm{cm}^{2}$ gücündeki LED ışık cihazı Elipar S 10 (3M ESPE, St. Paul, MN, Amerika) kullanılmıştır. Her bir örnek ile 20 sn süreyle üst ve alt yüzlerinden polimerize edilmiştir. Polimerizasyon işleminin tamamlanmasının ardından tüm örnekler $37^{\circ} \mathrm{C}$ distile suda 24 saat süre ile bekletilmiştir. 24 saatin sonunda her bir örneğin üst yüzeyi standart bir yüzey sağlamak amacı ile sırası ile 600 ve 1200 gritlik SIC zımparalar ile 30 sn boyunca zımparalanmıştır.

Tablo1. Çalışmada kullanılan kompozit rezin materyaller ve içerikleri.

\begin{tabular}{|c|c|c|c|}
\hline $\begin{array}{l}\text { Kompozit } \\
\text { Rezin }\end{array}$ & $\begin{array}{l}\text { Kompozit } \\
\text { Rezin tipi }\end{array}$ & $\begin{array}{l}\text { Organik } \\
\text { içerik }\end{array}$ & İnorganik içerik \\
\hline $\begin{array}{l}\text { Aelite LS } \\
\text { Posterior } \\
\text { (Bisco, } \\
\text { Schaumburg, } \\
\text { IL, Amerika) }\end{array}$ & $\begin{array}{l}\text { Hibrit } \\
\text { Kompozit } \\
\text { rezin }\end{array}$ & $\begin{array}{l}\text { Bis-EMA } \\
\text { TEGDMA }\end{array}$ & $\begin{array}{l}\text { Etoksile bisfenol-A } \\
\text { dimetakrilat } \\
\text { Trietilenglikol dimetakrilat } \\
\text { Cam doldurucu Amorf } \\
\text { Silika }(0.7 \mu \mathrm{m}) \\
\text { (ağırlıkca yüzdesi \%73.0, } \\
\text { hacimce \%53) }\end{array}$ \\
\hline $\begin{array}{l}\text { Beautifil- } \\
\text { Bulk } \\
\text { Restorative } \\
\text { (Shofu } \\
\text { Dental } \\
\text { Corporation, } \\
\text { San Marcos, } \\
\text { Amerika) } \\
\end{array}$ & $\begin{array}{l}\text { Giomer } \\
\text { esaslı } \\
\text { bulk-fill } \\
\text { kompozit } \\
\text { rezin }\end{array}$ & $\begin{array}{l}\text { Bis-GMA, } \\
\text { UDMA, } \\
\text { Bis-MEP, } \\
\text { TEGDMA }\end{array}$ & $\begin{array}{l}\text { Fluoro-silicate cam } \\
\text { (ağırlıkca yüzdesi \%87.0, } \\
\text { hacimce \%74.5) }\end{array}$ \\
\hline $\begin{array}{l}\text { Beautifil II } \\
\text { (Shofu } \\
\text { Dental } \\
\text { Corporation, } \\
\text { San Marcos, } \\
\text { Amerika) }\end{array}$ & $\begin{array}{l}\text { Giomer } \\
\text { kompozit } \\
\text { rezin }\end{array}$ & $\begin{array}{l}\text { Bis-GMA, } \\
\text { TEGDMA, } \\
\text { UDA }\end{array}$ & $\begin{array}{l}\text { S-PRG filler, MF (Multi- } \\
\text { functional) cam } \\
\text { doldurucu, Discrete nano } \\
\text { doldurucu }\end{array}$ \\
\hline \multicolumn{4}{|c|}{$\begin{array}{l}\text { Bis-EMA: ethoxylated bisphenol A glykol dimethacrilate; Bis-GMA: } \\
\text { bisphenol A glycidyl methacrylate; UDMA: urethane dimethacrylate; Bis- } \\
\text { MEP: bis(2-(methacryloyloxy)ethyl) phospate; TEGDMA: triethylene } \\
\text { glycol dimethacrylate; UDA: urethane diacrylate; S-PRG: surface reaction } \\
\text { type pre-reacted glass-ionomer (önceden yüzey reaksiyonuna girmiş cam } \\
\text { iyonomer). }\end{array}$} \\
\hline
\end{tabular}

Bu çalışmada beyazlatma ajanı olarak, gece koruyuculu beyazlatma ajanı olan \%16'lık Opalescence PF (Ultradent, South Jordan, UT, Amerika) kullanımıştır. Bu madde saydam, aromalı, yüksek viskoziteli, yapışkan, \%16 (\%5,8 HP) karbamid peroksit jelidir ( $\mathrm{pH} ~ 6,5) . \% 16$ Opalescence PF karbamid peroksit jel, potasyum nitrat ve $\% 0,11$ (1100 ppm) florür içerir.

$\mathrm{Bu}$ çalışmada kullanılan her bir materyalinden hazırlanmış olan 30'ar adet disk (toplamda 90) 3 alt gruba ayrılmıştır $(n=10)$. Birinci grupta yer alan örneklerin yüzey pürüzlülük ölçümleri zımparalama işleminin ardından yapılmıştır. İkinci grupta yer alan örneklere \%16 Opalescence PF 7 gün boyunca günde 4 saat uygulanırken; üçüncü gruba yer alan örneklere \%16 Opalescence PF 7 gün boyunca günde 6 saat uygulanmıştır. Beyazlatma ajanı, üretici firmaların talimatları doğrultusunda uygulanmıştır.

Örneklerin yüzey pürüzlülüğü ölçümleri için profilometre cihazı (Surtronic S128, Taylor Habson Ltd., Leicester, İngiltere) kullanıldı. $5 \mu \mathrm{m}$ çapındaki elmas uç her bir örneğe dik olarak $\left(90^{\circ}\right)$ konumlandırıldı. Cihaz kalibre edildikten sonra elmas ucun "cut-off" değeri $0.25 \mathrm{~m}$ olarak ayarlandı. Örneklerin merkezinden olacak şekilde her bir örnekten 5 ölçüm yapılıp, elde edilen verilerin $(\mathrm{Ra}, \mu \mathrm{m})$ ortalamaları alınarak her bir numune için ortalama yüzey pürüzlülük değerleri hesaplandı.

İstatistiksel değerlendirme, IBM SPSS 20.0 (SPSS Inc., Chicago, IL, Amerika) programı ile yapıldı. Normal dağılıma uygunluk testi Kolmogorov-Smirnov Testi ile değerlendirildi. Normal dağılım gösteren nümerik değişkenler Ortalama +/- standart sapma olarak verildi. Veriler, iki yönlü varyans analizi (ANOVA) ve Tukey's HSD post-hoc testi ile istatistiksel olarak analiz edildi. $p<0.05$ istatistiksel olarak önemlilik için yeterli kabul edildi.

\section{BULGULAR}

$\mathrm{Bu}$ çalışmadan elde edilen bulgular Tablo 2'de gösterilmiştir. İki yönlü ANOVA sonuçlarına göre; başlangıç zaman dilimi olan Grup 1'de Beautifil-Bulk Restorative, Beautifil II ve Aelite LS Posterior materyalleri istatistiksel olarak benzer yüzey pürüzlülük sonuçları sergilemiştir ( $p>0.05$ ). Grup 2 ve Grup 3'de de bu üç materyal istatistiksel olarak benzer sonuçlar sergilemiştir ( $p>0.05)$.

Her bir materyalin gruplar arası kıyaslaması yapıldığında, Aelite LS Posterior ve Beautifil-Bulk Restorative için Grup 1, Grup 2 ve Grup 3'den elde edilen değerler istatistiksel olarak benzer bulunmuştur. Ancak, Beautifil II'den elde edilen yüzey pürüzlülük değerlerine göre; 7 gün boyunca günde 6 saat süresince \%16 Opalascense PF beyazlatma uygulaması yapılan gruptan (Grup 3) elde edilen yüzey pürüzlülük değerleri, başlangıç grubundan elde edilen değerlerden (Grup 1) anlamlı olarak yüksek bulunmuştur $(p<0.05)$. Günde 4 saat ve 6 saat $\% 16$ Opalascense PF beyazlatma ajanı uygulanan örneklerden 1 hafta sonra elde edilen Ra değerleri arasında (Grup 2 ve Grup 3) 
anlamlı bir farklıık bulunamamışıı ( $p>0.05)$.

Tablo 2. Çalışmada elde edilen yüzey pürüzlülük değerleri $(\mathrm{Ra}, \mu \mathrm{m})$, ortalama ve standart sapmaları.

\begin{tabular}{|c|c|c|c|}
\hline Gruplar & $\begin{array}{l}\text { Aelite }^{\mathrm{TM}} \text { LS } \\
\text { Posterior } \\
\text { (ortalama } \pm \\
\text { standart } \\
\text { sapma) }\end{array}$ & \begin{tabular}{|l|} 
Beautifil- \\
Bulk \\
Restotative \\
(ortalama \pm \\
standart \\
sapma) \\
\end{tabular} & $\begin{array}{l}\text { Beautifil II } \\
\text { (ortalama } \pm \\
\text { standart } \\
\text { sapma) }\end{array}$ \\
\hline $\begin{array}{l}\text { Grup 1 } \\
\text { (Bašlangıç } \\
\text { değerleri) }\end{array}$ & $0.87 \pm 0.149^{\mathrm{A1}}$ & $0,70 \pm 0.133^{\mathrm{A1}}$ & $0.65 \pm 0.184^{\mathrm{A1}}$ \\
\hline $\begin{array}{l}\text { Grup 2 } \\
\text { (7 gün } \\
\text { boyunca } \\
\text { günde } 4 \text { saat } \\
\% 16 \\
\text { Opalascense } \\
\text { PF } \\
\text { beyazlatma } \\
\text { uygulaması) }\end{array}$ & $0.89 \pm 0.347^{\mathrm{A} 1}$ & $0.74 \pm 0.183^{\mathrm{A} 1}$ & $0.94 \pm 0.287^{\mathrm{AB}}$ \\
\hline $\begin{array}{l}\text { Grup } 3 \\
\text { ( } 7 \text { gün } \\
\text { boyunca } \\
\text { günde } 6 \text { saat } \\
\% 16 \\
\text { Opalascense } \\
\text { PF } \\
\text { beyazlatma } \\
\text { uygulaması) }\end{array}$ & $0.77 \pm 0.245^{\mathrm{A1}}$ & $0.74 \pm 0.236^{\mathrm{A1}}$ & $0.95 \pm 0.474^{B 1}$ \\
\hline
\end{tabular}

\section{TARTIŞMA}

$\mathrm{Bu}$ çalışmada her üç materyal istatistiksel olarak benzer yüzey pürüzlülük değerleri sergilemiştir. $\mathrm{Bu}$ nedenle bu çalışmada oluşturulan birinci hipotez "Giomerler geleneksel kompozit rezinlerden yüksek pürüzlülük değerleri sergilerler" reddedilmiştir. Çalışmamızda oluşturulan ikinci hipotez "Giomerler gece koruyuculu beyazlatma ajanı olan \%16'ık karbamid peroksit Opalescence PF uygulaması sonrasında yüzey pürüzlülük artışı sergilemezler" kısmen kabul edilmiştir. Beautifil-Bulk Restorative \%16'lık karbamid peroksit Opalescence PF uygulaması sonrasında anlamlı bir yüzey pürüzlülük artışı sergilemezken, Beautifil II anlamlı bir yüzey pürüzlülük artışı sergilemiştir. Çalışmamızda oluşturulan üçüncü hipotez "\%16 karbamid peroksit Opalescence PF'nin 1 hafta süresince günde 4 ya da 6 saat uygulanması bu üç materyalin yüzey pürüzlülük sonuçlarını etkilemez" kısmen kabul edilmiştir. Bir hafta süresince günde 4 saat $\% 16$ karbamid peroksit Opalescence PF uygulaması üç materyalinde yüzey pürüzlülük değerlerini anlamlı olarak arttırmazken, bir hafta süresince günde 6 saat $\% 16$ karbamid peroksit Opalescence PF uygulaması Beautifil
II'nin yüzey pürüzlülük değerlerini anlamlı olarak arttırmıştır.

Beyazlatma ajanlarının yüzey özelliklerini değiştirdiğini ele alan in vitro çalışmalar, uygulanan beyazlatma maddelerinin kontrolsüz kullanılmasının diş sert dokularında kayıplara ${ }^{22}$ ve mine hasarına yol açabileceğini bildirmiştir. Uygulanan beyazlatma ajanlarının asiditesindeki $(\mathrm{pH})$ farklılıkların 4 ile 7 arasında olduğu ve düşük $\mathrm{pH}$ değerlerinin mineye çeşitli düzeylerde hasar verebileceği bildirilmiştir. ${ }^{23} \mathrm{Bu}$ nedenle yapılan beyazlatma işlemlerinin ardından florür uygulanması genellikle önerilmektedir. ${ }^{24}$ Bunun yanı sıra, tükürükteki minerallerle remineralizasyon işlemi sonucu kayıp mineraller kısmen yerine gelmektedir. ${ }^{25}$

Bu çalışmada bir gece koruyuculu beyazlatma ajanının, farklı restoratif materyallerin yüzey pürüzlülük değerleri üzerindeki etkisi incelenmiştir. Pürüzlü restorasyon yüzeyleri renklenme, plak retansiyonu gibi problemlere yol açması açısından önemlidir. Yapılan bir çalışmada, plak retansiyonunun 0.7 ila 1.4 Ra değerleri aralığında gerçekleştiği belirtilmiştir. ${ }^{26}$ Bakterilerin bağlanması için kritik yüzey pürüzlülük değerinin ise $0.2 \mathrm{Ra}^{26,27}$ olduğu bildirilmiştir.

Kompozit rezinler söz konusu olduğunda, beyazlatma ajanları organik matriksi, doldurucuları ya da her ikisini birden etkileyebilir ve materyalin bozulmasına veya çözünmesine yol açabilir. Ancak, inorganik doldurucular genellikle cam veya seramik parçacıklardan meydana geldiği için hidrojen peroksitin doldurucular üzerindeki etkisi oldukça az olmaktadır. Bunun yanında, organik matriks hidrojen peroksitin yüksek konsantrasyonlarda veya sıklikla uygulanması sonucunda kimyasal olarak yıkıma uğrayabilir. ${ }^{28}$ Yüksek konsantrasyondaki hidrojen peroksitin restorasyonların yüzeylerinde pürüzlülük oluşturduğu yapılan çalışmalarla gösterilmiştir.

Cengiz ve arkadaşlarının yaptığı çalışmada, $\% 10^{\prime}$ luk hidrojen peroksit ve \%10'luk karbamid peroksit içeren iki gece koruyuculu beyazlatma ajanı kullanılmışır. ${ }^{29}$ Bu çalışmanın bulguları, (kontrol grubuna kıyasla) her iki beyazlatma ajanının, test edilen tüm materyallerin yüzey pürüzlülüğünde istatistiksel olarak önemli bir artı̧̧a neden olduğunu ortaya koymuştur. Bu çalışmada kullanılan kompozit rezin materyaller Reflexions XLS, Grandio; Grandio Direct; Clearfil Majesty Esthetic; Ceram-X-mono'dur. ${ }^{38}$ Bu sonuç, hidrojen peroksitin, kompozit rezinin hidrolitik bozulmasını hızlandırmasından sorumlu olabileceğini destek- 
leyen çalışmalarla tutarlıdır. ${ }^{30-33}$ Peroksitlerin, polimer zincirlerinin oksidatif olarak bölünmesine sebep olduğu ve organik matriks ile inorganik doldurucu maddeler arasındaki bağlanmanın bozulmasına yol açtığı ve bunların kompozit rezinlerin yüzey pürüzlülüğündeki artış ile ilişkili olduğu iddia edilmiştir. ${ }^{32,34}$ Öte yandan, bazı çalışmalarda ise beyazlatma ajanının mikro dolgulu, hibrid ve posterior kompozit rezin restoratif materyallerin yüzey pürüzlülüğü üzerinde anlamlı bir etkisinin olmadığı sonucuna varılmıştır. Bulgular arasındaki tutarsızlıklar, değerlendirilen kompozit rezin materyallerin içeriğinin farklııılarından kaynaklanıyor olabilir. ${ }^{35,36}$

Yüzügüllü ve arkadaşları, 3 farklı kompozit rezin üzerinde \%20 karbamit peroksit içeren beyazlatıcı ajanı 8 gün boyunca uygulamışlar ve beyazlatma ajanın yüzey pürüzlülüğü açısından anlamlı bir fark oluşturmadığını bildirmişlerdir. ${ }^{36}$ Wattanapayungkul ve arkadaşları, ${ }^{37}$ evde uygulanan beyazlatıc ajanların uygulama sürelerinin artması sonucunda, restoratif materyallerin yüzey pürüzlülük değerlerinde artış olduğunu göstermişlerdir. Araştırmacılar, kompozit rezinleri günde 8 saat boyunca $\% 10^{\prime} l u k$ ve $\% 15^{\prime}$ lik karbamid peroksite maruz bırakmışlar ve çalışmanın sonucunda, restoratif materyaller üzerinde beyazlatma ajanlarının, yüzey pürüzlülüğü açısından etkilerinin maruz kalınan zamana ve kullanılan materyale bağlı olarak değiştiğini rapor etmişlerdir. ${ }^{37}$ Çalışmamızda kullanılan \%16 karbamid peroksit Opalescence PF, üretici firmanın önerileri doğrultusunda uygulama süresi olan 7 gün boyunca günde 4 veya 6 saat olmak üzere iki farklı zaman diliminde uygulanmıştır. Çalışmamızın bulgularına göre daha uzun süreli beyazlatma ajan uygulamalarının, giomer veya posterior kompozit rezinler üzerinde farklı sonuçlar yaratabileceği düşünülebilir. Farklı üç materyale uygulanan bu işlem sonucunda Beautifil II'de anlamlı oranda yüzey pürüzlülük artışı tespit edilmiştir. Evde uygulanan beyazlatıcı ajanların etkileri düşünülerek, uzun süreli uygulamaların da incelenmesinde fayda olabilir.

Attin ve arkadaşları yaptıkları sistematik derlemede, hidrojen peroksitin kompozit rezinlerin mikrosertliğini etkileyebileceğini bildirmişlerdir.$^{38}$ Yap ve Wattanapayungkul, Spectrum TPH, Dyract AP, PRG (Reactmer) materyallerin yüzey sertlik ölçümlerini, iki farklı ofis beyazlatma tekniği uygulamasının (\%35 karbamid peroksit ve \%35 hidrojen peroksit) arkasından ölçmüşler. Araştırmacılar, resin-modifiye camiyonomer, polyacid-modifiye kompozit rezin ve PRG giomer materyallerin yüzey sertlik değerlerinde beyazlatma ajanı uygulamasının arkasından anlamlı bir değişiklik olmadığını ifade etmişlerdir. ${ }^{39}$ Beyazlatma ajanlarının materyallerin yüzey pürüzlülüğü, yüzey sertliği ve bağlanma gücünü etkileyip etkilemediği tartışmalı konudur. Bazı çalışmalar, restorasyonların yüzey özelliklerinin beyazlatma maddeleri tarafından etkilenmediğini belirtirken, ${ }^{35,39,40}$ bazıları ise beyazlatma ajanlarının materyallerin yüzey özelliklerini değiştirdiğini rapor etmiştir. ${ }^{41,42}$ Beyazlatma maddelerinin uygulanmasından sonra mevcut restoratif materyallerin bozulması, restorasyonların klinik dayanıklılı̆ını etkileyebilir. Klinik olarak, beyazlatma ajanları, restoratif materyallerin mikrosertliklerinde azalmaya neden olabilir, ${ }^{43}$ kompozit rezin restorasyonlar üzerinde makroskobik olarak değişiklikler olmadığı düşünülse bile, mikroskobik değişiklikler yaratabilir. Dolayısıyla materyallerin uygun zamanlama ile kullanılması klinik açıdan önemlidir. Bu nedenle güncel restoratif materyaller ile ilgili ilave çalışmalara intiyaç vardır.

\section{SONUÇ}

Hastalar tarafından sıklıkla tercih edilen gece koruyuculu beyazlatma ürünlerinden biri olan düşük konsantrasyonlardaki karbamit peroksitin, iki farklı zaman diliminde, üç farklı tipte restoratif materyale uygulanmasının arkasından yapılan yüzey pürüzlülük incelemesinde, hibrit kompozit rezin Aelite LS Posterior ve giomer esaslı Beautifil-Bulk Restorative'in yüzey pürüzlülük değerleri anlamlı olarak değişmemiştir. Ancak giomer esaslı Beautifil II'nin yüzey pürüzlülük değerleri \%16' lık karbamid peroksit Opalescence PF'nin 1 hafta süresince günde 6 saat uygulamasının ardından anlamlı olarak artmıştır.

Dilan KARA: ORCID ID: 0000-0003-2979-6068

Neslihan TEKÇE: ORCID ID: 0000-0002-5447-3159

Aslıhan KOCCAK: ORCID ID: 0000-0002-6748-6530

Emre ÖZEL: ORCID ID: 0000-0003-1883-5172

\section{KAYNAKLAR}

1. Campos I, BRISO AL, Pimenta LAF, Ambrosano G. Effects of bleaching with carbamide peroxide gels on microhardness of restoration materials. J Esthet Restor Dent 2003; 15: 175-83.

2. Haywood VB, Heymann HO. Nightguard vital bleaching. Quintessence Int 1989; 20: 173-6. 
3. Mujdeci A, Gokay O. Effect of bleaching agents on the microhardness of tooth-colored restorative materials. J Prosthet Dent 2006; 95: 286-9.

4. Carey CM. Tooth whitening; What we now know. J Evid Based Dent Pract 2014; 14: 70-6.

5. Basson RA, Grobler SR, Kotze TJ, Osman Y. Guidelines for the selection of tooth whitening products amongst those available on the market. SADJ 2014; 68: 122-9.

6. Marson FC, Sensi LG, Vieira LC, Araujo E. Clinical evaluation of in-office dental bleaching treatments with and without the use of light-activation sources. Oper Dent 2008; 33: 15-22.

7. Joiner $A$. The bleaching of teeth. A review of the literature. J Dent 2006; 34: 412-9.

8. Auschill TM, Hellwig E, Schmidele $S$, Sculean A, Arweller UB. Efficacy, side-effects and patients' acceptance of different bleaching techniques (OCT, in-office, at-home). Oper Dent 2005; 30: 156-63.

9. Lie T. Early dental plaque morphogenesis. A scanning electron microscope study using the hydroxyapatite splint model and a low-sucrose diet. J Periodontal Res 1977; 12: 73-89.

10. Nyvad B, Fejerskov O. Scanning electron microscope of early microbial colonization of human enamel and root surfaces in vivo. Scand J Dent Res 1987; 95: 287-96.

11. Quirynen M, Marechal M, Busscher $\mathrm{HJ}$, Weerkamp $\mathrm{AH}$, Darius $\mathrm{PL}$, van Steenberghe $\mathrm{D}$. The influence of surface free energy and surface roughness on early plaque formation. An in vivo study in man. J Clin Periodontol 1990; 17: 138-44.

12. Quirynen M, Bollen CML, Papaioannou W, Van Eldere JV, van Steenberghe $D$. The influence of titanium abutment surface roughness on plaque accumulation and gingivitis: Short-term observations. Int J Oral Maxillofac Implants 1996; 11: 169-78.

13. Haywood VB, Heymann HO. Nightguard vital bleaching: how safe is it? Quintessence Int 1991; 22: 515-23.

14. Denehy GE, Swift EJ Jr. Single-tooth home bleaching. Quintessence Int 1992; 23: 595-8.

15. Kawai K, Urano M. Adherence of plaque components to different restorative materials Oper Dent 2001; 26: 396-400.

16. Fleming GJ, Awan M, Cooper PR, Sloan AJ. The potential of a resin-composite to be cured to a 4 mm depth. Dent Mater 2008; 24: 522-9.

17. Papadogiannis D, Tolidis K, Gerasimou P, Lakes R, Papadogiannis $\mathrm{Y}$. Viscoelastic properties, creep behavior and degree of conversion of bulk fill composite resins. Dent Mater 2015; 31: 1533-41.

18. Ilie N, Hickel R. Investigations on a methacrylatebased flowable composite based on the $\mathrm{SDR}^{\mathrm{TM}}$ technology. Dent Mater 2011; 27: 348-55.

19. Marovic D, Tauböck TT, Attin T, Panduric V, Tarle Z. Monomer conversion and shrinkage force kinetics of low-viscosity bulk-fill resin composites. Acta Odontol Scand 2015; 73: 474-80.

20. Ilie N, Stark K. Curing behavior of high-viscosity bulk-fill composites. J Dent 2014; 42: 977-85.

21. Roberts T, Miyai K, Ikemura K, Fuchigami K, Kitamura, T. Fluoride ion sustained release preformed glass ionomer filler and dental compositions containing the same. United States Patent No. 5,883,153, 1999.

22. Wandera A, Feigal RL, Douglas WH, Pintado MR. Home use tooth bleaching agents: $A n$ in vitro study on quantiative effect on enamel, dentin and cementum. Quintessence Int 1994; 25: 541-6.

23. Shannon $H$, Spencer $P$, Gross K, Tira D. Characterizatin on enamel exposed to \%10 carbamid peroxide blezhing agents. Quintessence Int 1993; 24: 39-44.

24. Attin $\mathrm{T}$. The security and use of carbamid perozide gels in bleaching therapy. Dtsch Zahnarztl Z 1998; 53: $11-6$.

25. Rotstein I. Role of catalase in the elimination of resudial hydrogen peroxide following tooth bleaching. J Endod 1993; 19: 567-9.

26. Weitman RT, Eames WB. Plaque accumulation on composite surfaces after various finishing procedures. Oral Health 1975; 65: 29-33.

27. Jones CS, Billington RW, Pearson GJ. The in vivo perception of roughness of restorations. $\mathrm{Br}$ Dent J 2004; 196: 42-5.

28. Kim JH, Lee YK, Lim BS, Rhee SH, Yang HC. Effect of tooth-whitening strips and films on changes in color and surface roughness of resin composites. Clin Oral Investig 2004; 8: 118-22.

29. Cengiz E, Kurtulmuş-Yılmaz S, Ulusoy N, Deniz S. $T$, Yüksel-Devrim E. The Effect of home bleaching agents on the surface roughness of five different composite resins: A SEM evaluation. Scanning 2016; 38: 277-83. 
30. Basting RT, Fernandez Y Fernandez C, Ambrosano GM, de Campos IT. Effects of a $10 \%$ carbamide peroxide bleaching agent on roughness and microhardness of packable composite resins. J Esthet Restor Dent 2005; 17: 256-62.

31. Gürgan S, Yalcin F. The effect of two different bleaching regimens on the surface roughness and hardness of tooth- colored restorative materials. Quintessence Int 2007; 38: 83-7.

32. Rattacaso RM, da Fonseca Roberti Garcia L, Aguilar FG, Consani S, de Carvalho Panzeri Pires-de Souza F. Bleaching agent action on color stability, surface roughness and microhardness of composites submitted to accelerated artificial aging. Eur J Dent 2011; 5: 143-9.

33. Wang L, Francisconi LF, Atta MT, Dos Santos JR, Del Padre NC, Gonini A Jr, Fernandes KB. Effect of bleaching gels on surface roughness of nanofilled composite resins. Eur J Dent 2011; 5: 173-9.

34. Hafez R, Ahmed D, Yousry M, El-Badrawy W, ElMowafy O. Effect of in-office bleaching on color and surface roughness of composite restoratives. Eur J Dent 2010; 4: 118-27.

35. Langsten RE, Dunn WJ, Hartup GR, Murchison DF. Higher-concentration carbamide peroxide effects on surface roughness of composites. J Esthet Restor Dent 2002; 14: 92-6.

36. Yüzügüllü B , Çelik Ç , Erkut S. Karbamid peroksit içeren beyazlatma ajanının kompozit rezinlerin yüzey pürüzlülüğüne etkisi . Atatürk Üniv. Dis Hek. Fak. Derg 2008; 18: 94-8.

37. Wattanapayungkul P, Yap AU, Chooi KW, Lee MF, Selamat RS, Zhou RD. The effect of home bleaching agents on the surface roughness of tooth-colored restoratives with time. Oper Dent 2004; 29: 398-403.

38. Attin T, Hannig C, Wiegand A, Attin R. Effect of bleaching on restorative materials and restorations a systematic review. Dent Mater 2004; 20: 852-61.

39. Yap AU, Wattanapayungkul P. Effects of in-office tooth whiteners on hardness of tooth-colored restoratives. Oper Dent 2002; 27: 137-41.

40. Türker SB, Biskin T. Effect of three bleaching agents on the surface properties of three different esthetic restorative materials. J Prosthet Dent 2003; 89: 446-73.
41. García-Godoy F, García-Godoy A, García-Godoy F. Effect of bleaching gels on the surface roughness, hardness, and micromorphology of composites. Gen Dent 2002; 50: 247-50.

42. Bailey SJ, Swift EJ Jr. Effects of home bleaching products on composite resins. Quintessence Int 1992; 23: 489-94.

43. Kao EC, Peng P, Johnston WM. Color changes of teeth and restorative materials exposed to bleaching. J Dent Res 1991; 70 Abstract \#2436 p 570.

\section{Yazışma Adresi}

Doç. Dr. Neslihan TEKÇE

Kocaeli Üniversitesi Diş Hekimliği Fakültesi

Restoratif Diş Tedavisi Anabilim Dalı

Yuvacık, Başiskele

KOCAELİ

Tel: 02623442111

Faks: 02623442202

e-mail: neslihan_arslann@hotmail.com 